\title{
Evaluation of the Performance of Conventional Water-Based Mud Characteristics by Applying Zinc Oxide and Silica Dioxide Nanoparticle Materials for a Selected Well in the Kurdistan/Iraq Oil Field
}

\author{
Ahmed R. AlBajalan $\mathbb{D}^{1}$ and Hunar K. Haias ${ }^{2}$ \\ ${ }^{1}$ Department of Petroleum Technology, Erbil Polytechnic University, Erbil, Iraq \\ ${ }^{2}$ Ministry of Natural Resources, Erbil, Iraq \\ Correspondence should be addressed to Ahmed R. AlBajalan; ahmed.al_bajalan@epu.edu.iq
}

Received 16 April 2021; Accepted 21 July 2021; Published 28 July 2021

Academic Editor: Francesco Ruffino

Copyright $\odot 2021$ Ahmed R. AlBajalan and Hunar K. Haias. This is an open access article distributed under the Creative Commons Attribution License, which permits unrestricted use, distribution, and reproduction in any medium, provided the original work is properly cited.

\begin{abstract}
Nanomaterials have gained a wide interest in the oil and gas industry due to their immense applicability. Nanomaterials are being used to formulate a new generation of drilling mud known as Nanomud or Smart mud, where it has the ability to improve mud properties and eliminate borehole problems. Using nanoparticles as an additive agent in conventional drilling mud can lead to a more efficient drilling process in troublesome formations. In this study, several conventional water-based muds from a selected well drilled in the Kurdistan/Iraq oil field have been prepared. Then, nanodrilling muds were formulated by dispersing $\mathrm{SiO}_{2}$ and $\mathrm{ZnO}$ nanoparticles in concentrations ranging from 0.25 to $1 \mathrm{wt}$.\% to conventional water-based mud (WBM). This study aims to evaluate and compare the performance of conventional water-based muds after adding $\mathrm{SiO}_{2}$ and $\mathrm{ZnO}$ nanoparticles. This evaluation was performed by carrying out a series of laboratory experiments to determine the rheological and mud filtrate properties. The results demonstrated that nanomuds improved the rheological behaviors and provided better filtration control compared to conventional drilling muds. However, there was little or no impact of the nanomaterials on the mud density for all mud systems.
\end{abstract}

\section{Introduction}

Drilling fluid, or drilling mud, is an integral component of the drilling process. Generally, the mud is pumped from the surface to the bottom of the well, and it passes through the drilling string (drill pipe, drill collar) and the bit. Then, it returns back to the surface through the annular space between the drilling string and the borehole [1]. Primarily, drilling fluids are used for cooling and lubricating the drilling bit and the drilling string, suspending the rock cutting when the circulation is paused, carrying out the rock cutting from borehole to the surface, and maintaining the hydrostatic head pressure $(\mathrm{Ph})$ greater than the pore pressure $(\mathrm{Pf})$ to avoid any kind of unwanted formation fluids to flow to the well $[2,3]$.
Generally, drilling mud is one of the most essential aspects to be considered during the well construction and completion stages. The proper selection of the drilling mud is one of the key factors for succussing any drilling operation, which is typically based on its performance, cost, and environmental influence. On the other hand, improper drilling mud design may cause several drilling problems such as pipe sticking, mud loss, kick, bit balling, and borehole collapse [3].

Water-based drilling muds (WBMs) and oil-based drilling muds (OBMs) are two main types of drilling muds that are widely used during drilling operations. For instance, in the Kurdistan/Iraq fields, the WBMs are the most applied mud during drilling operations because it is cheap, ecofriendly, and easy to prepare in comparison with oil-based 
mud. However, the WBM is not a good candidate when we drill through troublesome (shale) formation and it should be changed to OBM since it has a better shale inhibition and more tolerability to high-temperature and high-pressure formation. Nevertheless, the application of oil-based mud is restricted by its cost, environmental constraints, and regulations $[4,5]$.

Recently, nanotechnology has gained a wide range of interest in the oil and gas industry due to its immense applicability. Drilling fluids that contain at least one or more nanosized participles in their compositions are known as nano-drilling mud or smart mud.

Generally, the size of nanoparticles is ranging from 1 to $100 \mathrm{~nm}$ and they have a high specific surface area to volume ratio. The high surface area of NPs plays a significant role in minimizing the torque and drag forces. Since the NPs form a fine and thin lubricating layer around the pipe and wall interface, they also work as lubricants by reducing the friction between the drill string and wellbore. NPs also help to reduce the mud pump pressure. Furthermore, adding NPs to drilling muds can improve cutting transportation efficiency and thermal conductivity [6-8].

Additionally, the nanosized particles have better thermal and electrical characteristics compared to macro- and microsized particles. The physical and chemical characteristics of these particles also differ from the bulk material. These properties allow the drilling fluids to overcome the problems associated with the drilling operation. The small size of nanoparticles acts as a bridging agent; therefore, the small pores in the formation can efficiently seal and plug, which in turn prevent the loss of the fluid, especially in the shale formation [9].

Furthermore, the nanosized particles in the mud will enhance and stabilize the rheological properties of drilling mud, which eventually leads to improving the borehole cleaning and holding the drilling cutting. The nanobased drilling muds provide the solutions for a variety of borehole problems, including pipe sticking, loss of drilling fluid, formation damage, low standard of mud cakes, etc. [10].

However, poor dispersion of NPs under bottomhole conditions with a change in base fluid PH, salinity, and temperature can cause borehole instability and formation damage. Agglomeration is another problem as positively charged particles are exposed to acidic conditions and negatively charged particles are polluted with the base medium. Table 1 presents a summary of the main challenges that occurred during drilling operations and how the nanomud can solve them.

Several experimental studies were performed on the application of nanosized particles as an additive agent in drilling fluid formulations. According to William et al., adding small quantities of zinc oxide and copper oxide nanoparticles to the drilling mud enhanced the viscosity and thermal conductivity of the drilling mud [8]. In addition, research performed by Alvi et al. showed that ferric oxide nanoparticles improved filtration and filter cake properties and made the mud cake less porous [11]. In 2016, AL-Malki et al. found that the sepiolite nanosized particles would reduce the filtration volume and minimize the mud cake thickness under HPHT conditions [12].

A study by Geir Hareland investigated the effect of various concentrations of Iron hydroxide $\left(\mathrm{Fe}(\mathrm{OH})_{3}\right)$ and calcium carbonate $\left(\mathrm{CaCO}_{3}\right)$ nanosized particles on the rheological properties of oil-based mud (OBM). In their experimental study, they found that calcium carbonate NPs provided higher gel strength and plastic viscosity (PV) compared to the OBM sample without nanoparticles. They also concluded that iron oxide reduced the yield point value, but there was no or minimal effect of iron oxide on the plastic viscosity and gel strength. In addition, both NPs reduced mud filtration loss and created a thick mud cake [13].

Jung investigated the impact of two different sizes ( 3 and $30 \mathrm{~nm}$ ) of the $\mathrm{Fe}_{2} \mathrm{O}_{3}$ nanoparticle on the rheological and filtration characteristics of bentonite-based drilling mud (BBDF) at high-pressure and high-temperature (HPHT) environments. The study showed that the smaller size of NPs increased the plastic viscosity (PV) and yield point (YP) more than the bigger size [9].

The objective of this experimental study is to evaluate the performance of $\mathrm{SiO}_{2}$ and $\mathrm{ZnO}$ water-based nanomud characteristics and compare them with conventional waterbased mud. This evaluation was carried out through a series of laboratory tests.

\section{Methodology}

This study is based on laboratory experimental work, where six different types and weights of water-based drilling fluids (Spud mud, KCL-Polymer mud, and Salt KCL-Polymer mud) were formulated at actual temperature conditions. These muds have been used for drilling a well in the Kurdistan/Iraq oil field. The Well-A has faced several problems such as stuck pipe sticking and loss of drilling fluid, etc. Table 2 shows the types of drilling muds used during the drilling operation.

2.1. Conventional Drilling Fluid Formulation. The six conventional water-based drilling muds were formulated following the concept of maintaining the same properties and components used during drilling well-A.

The preparation procedure of conventional water-based mud is based on the Recommended Practice for Field testing WBDFs (API RP 13B), where 1 gram of solid material to $350 \mathrm{ml}$ of liquid in the lab scale is equal to adding $1 \mathrm{Ib}$ to 1 barrel of liquid at the field scale. The properties of the used conventional drilling muds while drilling well \#A are shown in Table 3.

The following sequences were used to prepare conventional WBM:

(1) Using fresh water as a base fluid.

(2) Adding Soda ash $\left(\mathrm{Na}_{2} \mathrm{CO}_{3}\right)$ into the water for contamination treatment. The mixture was stirred by using Hamilton Beach mixer for about 2 minutes. 
TABLE 1: Nanomud technical solutions.

\begin{tabular}{ll}
\hline Challenges & Nanomud solutions \\
\hline \multirow{3}{*}{ Shale instability } & Increase shale formation stability by \\
& (1) Minimizing the interaction between shale formation and drilling fluid by its ultrafine particles size \\
(2) Increasing the shale formation resistance to collapse and fracture \\
Minimize the differential pipe sticking by \\
(1) Forming a very fine filter cake
\end{tabular}

TABLE 2: Well-A drilling mud design.

\begin{tabular}{lcc}
\hline Hole size (inch) & Interval $(\mathrm{m})$ & Mud type \\
\hline 26 & $57-297$ & Spud mud \\
$171 / 2$ & $297-1002$ & KCL-polymer \\
$121 / 4$ & $1002-2341$ & KCL/Polymer \\
$81 / 2$ & $2341-3380$ & Salt/KCL/polymer \\
$81 / 2$ & $3145-4020$ & Salt/KCL/polymer \\
6 & $4020-4525$ & Salt/KCL/polymer \\
\hline
\end{tabular}

(3) At the end of 2 minutes, caustic soda $(\mathrm{NaOH})$ was added to increase the $\mathrm{PH}$ value of the mud.

(4) Bentonite (sg.gr 2.3) was added to the solution and stirred for 5 minutes to increase the viscosity.

(5) After that, the right amount of Barite $\left(\mathrm{BaSO}_{4}\right)$ (sp.gr 4.2) was added to the solution to increase the drilling fluid density and the stirring was continued for 35 minutes. The amount of barite required to prepare the desired mud weight was determined by using the following equation:

$$
\text { barite required }=1470 *\left[\frac{\rho 2-\rho 1}{35-\rho 2}\right] \text {, }
$$

where $\rho 1$ is the initial density in ppg and $\rho 2$ is the desired mud weight in ppg.

2.2. Formulation of Nano-WBM. To formulate the nanodrilling muds, the nanoparticles should disperse properly to avoid agglomeration and precipitation. For this purpose, an ultrasonic bath has been used. Then four various weight concentrations $(0.25 \%, 0.5 \% .0 .75 \%$, and $1 \%$ wt. $\%)$ of zinc oxide $(\mathrm{ZnO})$ and silica dioxide $\left(\mathrm{SiO}_{2}\right)$ nanomaterials are dispersed in distilled water added to conventional mud and mixed for 20 minutes. Then the mixture is exposed to an ultrasonic bath for 30 minutes at $40 \mathrm{kHz}$ and $180 \mathrm{~W}$ to guarantee good dispersion of nanoparticles inside the drilling mud, improve colloidal stability, and prevent agglomeration and participation of solid particles. The soda ash and caustic soda were used to keep the $\mathrm{pH}$ above 9. The characteristics of $\mathrm{ZnO}$ and $\mathrm{SiO}_{2}$ nanoparticles materials are shown in Table 4.

2.3. Experimental Measurements. The following mud properties have been measured and calculated for both conventional (base) fluid and nanodrilling muds:

(1) The mud weight (density) was measured by OFITE mud balance device.

(2) The rheological properties (i.e., plastic viscosity (PV), yield point (YP), and gel strength (GS)) were determined based on API RP13B - 12003 by using 6speeds electrical rotational viscometer (Model RC35D) after applying the following mathematical equations:

$$
\mathrm{PV}=\varnothing 600-\varnothing 300
$$

$\varnothing 600=$ dial reading at $600 \mathrm{rpm} \varnothing 300=$ dial reading at $300 \mathrm{rpm}$. Also,

$$
Y p=\varnothing 300-\mathrm{PV}
$$

(3) API fluid loss measurement: the standard API filter press device was used under 100 psi pressure. The experimental procedures are shown in Figure 1. The used equipment is shown in Figure 2.

\section{Results and Discussion}

In this study, the rheological properties and API filtration of 6 different conventional drilling muds used during drilling well \#A were examined with silica dioxide and zinc oxide nanoparticles at different ranges of concentrations $(0.25,0.5$, 0.75 , and $1 \mathrm{wt} . \%)$ and actual temperatures conditions. 
TABLe 3: Drilling mud design and properties.

\begin{tabular}{|c|c|c|c|c|c|c|}
\hline \multicolumn{7}{|c|}{ Well, \#A } \\
\hline Interval (m) & $57-297$ & $297-1002$ & $1002-2341$ & $2341-3380$ & $3145-4020$ & $4020-4525$ \\
\hline Mud type & $\begin{array}{c}\text { WBM } \\
\text { spud mud }\end{array}$ & $\begin{array}{c}\text { KCL/ } \\
\text { polymer }\end{array}$ & $\mathrm{KCL} /$ polymer & $\begin{array}{l}\text { Salt/KCL } \\
\text { polymer }\end{array}$ & Salt/KCL polymer & $\begin{array}{c}\text { Salt KCL/ } \\
\text { polymer }\end{array}$ \\
\hline Mud weight (ppg) & 9 & 10 & 9 & 9.5 & 9.2 & 9.4 \\
\hline Temp (F) & 120 & 120 & 120 & 120 & 120 & 120 \\
\hline Viscosity (sec/qt) & 54 & 57 & 65 & 50 & 50 & 55 \\
\hline $\mathrm{PV}(\mathrm{cP})$ & 16 & 15 & 18 & 15 & 15 & 20 \\
\hline $\mathrm{YP}\left(\mathrm{Ibs} / 100 \mathrm{ft}^{2}\right)$ & 29 & 27 & 28 & 22 & 22 & 22 \\
\hline Gels $\left(\mathrm{Ib} / 100 \mathrm{ft}^{2}\right) 10 \mathrm{sec}$ & 11 & 11 & 8 & 11 & 11 & 11 \\
\hline Gels $\left(\mathrm{Ib} / 100 \mathrm{ft}^{2}\right) 10 \mathrm{~min}$. & 17 & 18 & 13 & 13 & 18 & 13 \\
\hline $\mathrm{PH}$ & 10.4 & 10.5 & 10.5 & 10 & 10 & 10 \\
\hline APL FL (ml/30 min) & 0 & 6 & 6 & 15 & 15 & 6 \\
\hline CAKE API & 0.5 & NIL & NIL & 0.5 & & \\
\hline KCL wt.\% & NIL & $5 \%$ & $3 \%$ & $4 \%$ & $4 \%$ & $4 \%$ \\
\hline $\begin{array}{l}\text { Partially hydrolyzed } \\
\text { polyacrylamide (PHPA) } \\
\text { ppb }\end{array}$ & NIL & 1.5 & 1.5 & 0 & 0 & 0 \\
\hline Notes & & & $\begin{array}{l}\text { @ } 1500 \text { drilling string is } \\
\text { stuck due to cutting } \\
\text { accumulation } \\
\text { @1773 logging tool stuck }\end{array}$ & $\begin{array}{c}\text { @3314 pipe } \\
\text { stuck due to leg }\end{array}$ & $\begin{array}{l}@ 3350 \text { salt polymer } \\
\text { mud converted to } \\
\text { KCL mud }\end{array}$ & $\begin{array}{l}@ 4418 \text { the } 4 \frac{1}{2} \\
\text { liner got stuck }\end{array}$ \\
\hline
\end{tabular}

TABle 4: Characterization of $\mathrm{SiO}_{2}$ and $\mathrm{ZnO}$ nanoparticles.

\begin{tabular}{lccccc}
\hline Molecular formula & Purity (\%) & APS $(\mathrm{nm})$ & Specific surface area $\left(\mathrm{m}^{2} / \mathrm{g}\right)$ & Color & Density $\left(\mathrm{gm} / \mathrm{cm}^{3}\right)$ \\
\hline $\mathrm{SiO}_{2}$ & 99.5 & $15-20$ & $180-270$ & White & 2.4 \\
$\mathrm{ZnO}$ & 99.0 & $10-30$ & 88.89 & White/pale yellow & 5.6 \\
\hline
\end{tabular}
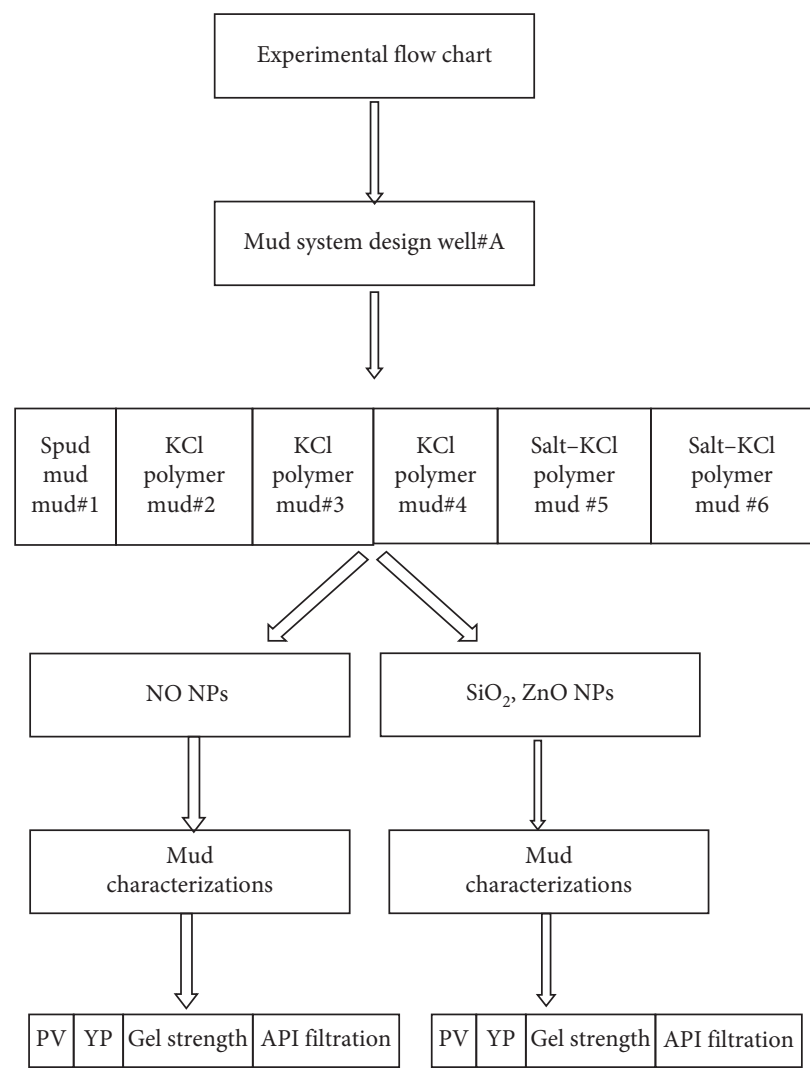

FIGURE 1: Experimental procedures. 


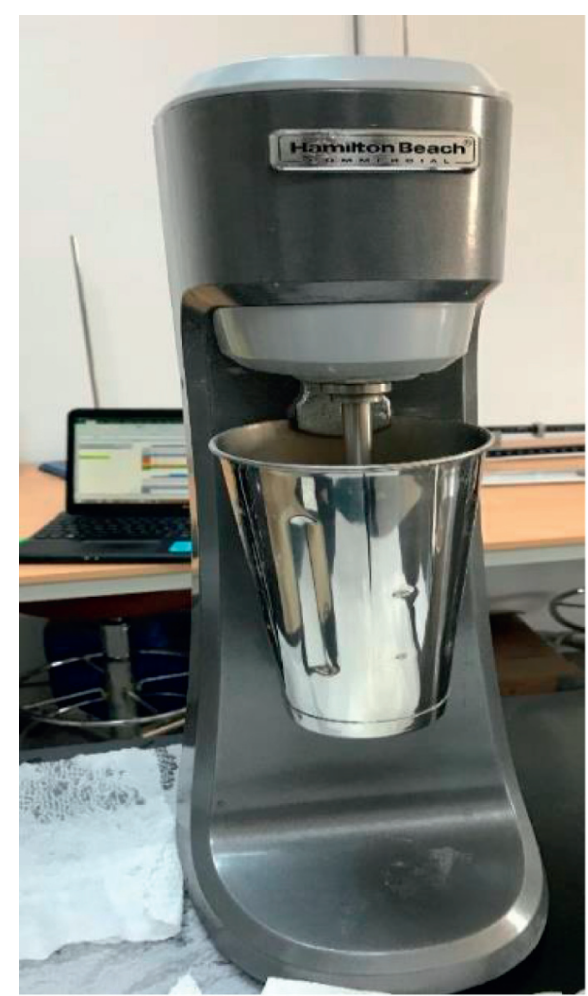

(a)

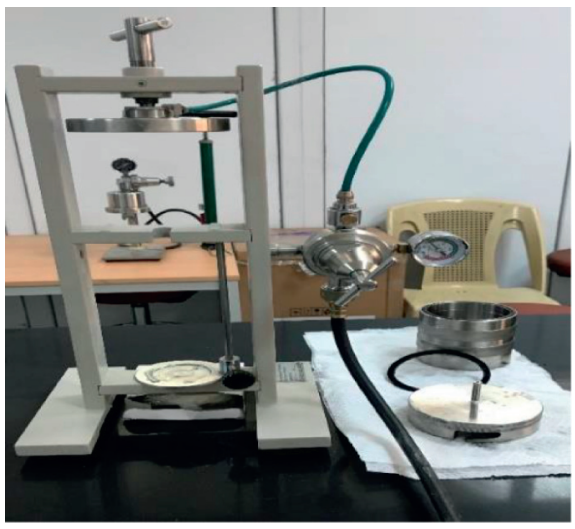

(c)

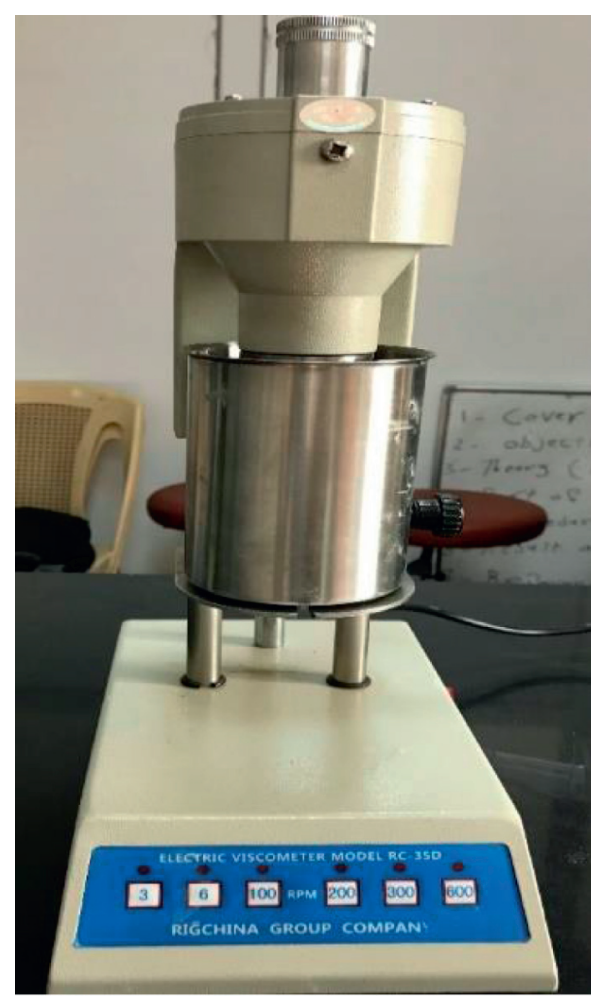

(b)

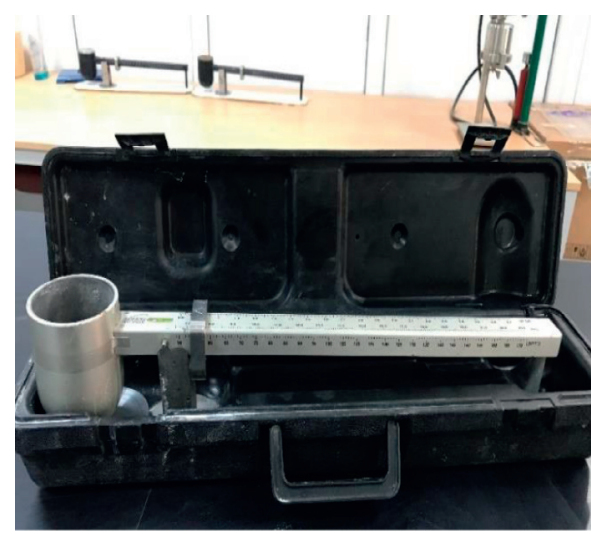

(d)

Figure 2: Laboratory apparatus. (a) Hamilton beach mixer. (b) Electric viscometer model RC35D. (c) API filter press. (d) OFITE mud balance.

\subsection{Rheological Characteristics}

3.1.1. Plastic Viscosity $(P V)$. The results demonstrate a significant impact of $\mathrm{SiO}_{2}$ and $\mathrm{ZnO}$ NPs on the plastic viscosity values for all mud systems where the PV values decrease with increasing nanosized particle concentrations from 0 to 1 wt.\%.

Figure 3(a) shows that as the concentration of $\mathrm{SiO}_{2} \mathrm{NP}$ was increased from 0 to $1 \mathrm{wt} . \%$ in the mud systems, the plastic viscosity values were reduced by $8 \%, 23 \%$, for drilling mud 1 and 2 . The reduction rate for mud systems $3,4,5$, and 6 was $25 \%, 28 \%, 21 \%$, and $15 \%$, respectively. A similar trend was observed for $\mathrm{ZnO}$ NPs Figure 3(b); however, the rate of reduction was less compared to $\mathrm{SiO}_{2} \mathrm{NP}$. For example, the $\mathrm{PV}$ values of mud samples 1 and 2 were reduced by $7.8 \%$ and
$22.5 \%$. For mud numbers $3,4,5$, and 6 , the reduction rates were $24 \%, 27.5 \%, 22 \%$, and $11 \%$, respectively.

These decreases in PV values are caused by the NPs distribution in the drilling mud, where they minimize the internal friction forces between particles, thereby minimizing the PV values. Reducing the PV value, minimize the pressure of the mud pump required for mud circulation, particularly when high density mud is required for drilling deep formation.

Nevertheless, it is significant to emphasize that reducing the PV values is beneficial to the drilling processes, where it promotes the penetration rate (ROP), diminishes or saves the energy required for drilling fluid circulation finally, and reduces the possibility of drilling fluid circulation loss to the formation fractures which resulted from the extreme (ECD) of the drilling fluid $[5,14]$. 


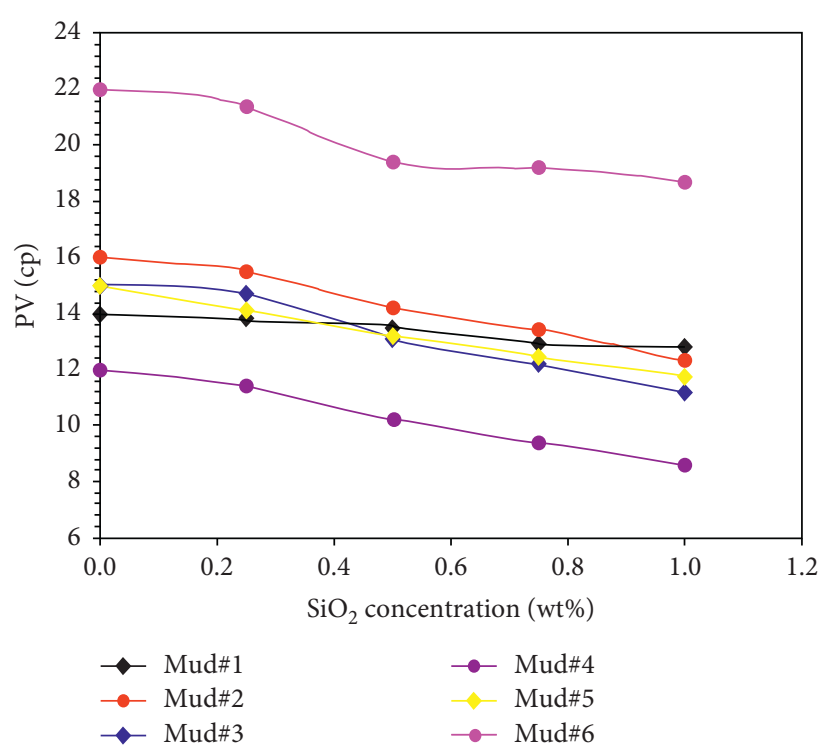

(a)

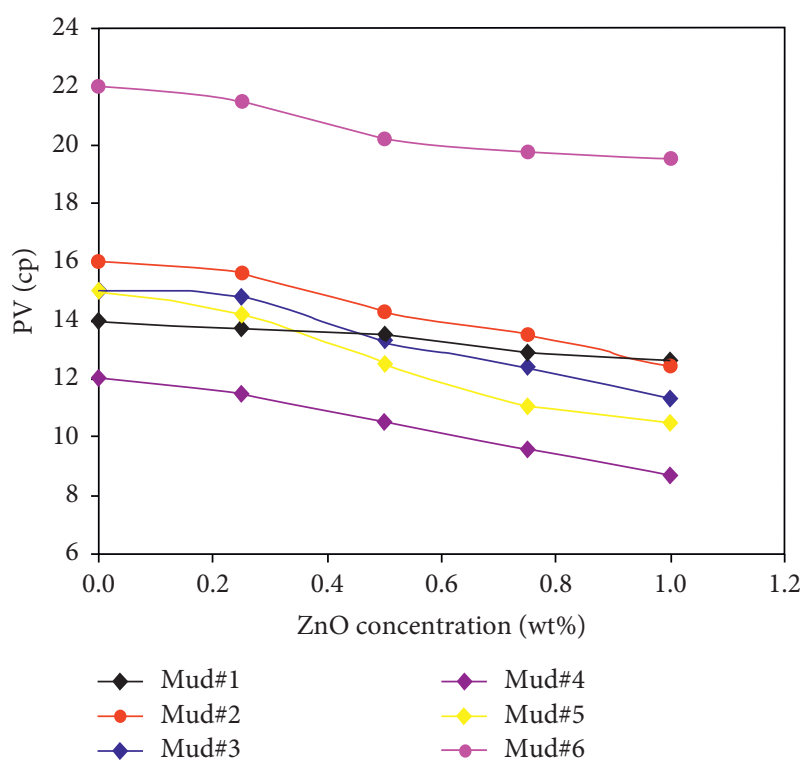

(b)

FIGURE 3: Comparison of plastic viscosity values for the conventional WBM system before and after adding different concentrations of (a) $\mathrm{SiO}_{2}$ NPs and (b) $\mathrm{ZnO}$ NPs.

3.1.2. Yield Point (YP). As demonstrated in Figures 4(a) and 4(b), the yield point (YP) values declined with increasing $\mathrm{SiO}_{2}$ and $\mathrm{ZnO}$ NPs concentrations. The results show that drilling fluids with high mud weight have a higher reduction in the yield point values compared to the lower density of other drilling fluid systems. As the mud weight increases, the resistance of the fluid to initiate flow increases.

For example, the rate of YP reduction for mud\#2 with $10 \mathrm{ppg}$ density is about $11 \%$ for $\mathrm{SiO}_{2}$ and 9.2 for $\mathrm{ZnO}$, whereas mud\#1 with 9 ppg mud weight showed the lowest reduction in $\mathrm{YP}$ values by $4.8 \%$ and $4.5 \%$ for $\mathrm{SiO}_{2}$ and $\mathrm{ZnO}$, respectively. The reason behind this reduction is that the $\mathrm{SiO}_{2}$ and $\mathrm{ZnO}$ NPs increase the distance among the solid particles in the drilling muds [5].

3.1.3. Mud Filtration. The small size of NPs can physically plug the pore throats of the formation; therefore, they reduce the filtration volume loss to the formation. The results in Figures 5(a) and 5(b) show that $\mathrm{SiO}_{2}$ and $\mathrm{ZnO}$ nanoparticles with different concentrations decrease the fluid loss over a period of 30 minutes.

It is observed that the filtration volume declined slightly with time by increasing $\mathrm{SiO}_{2}$ and $\mathrm{ZnO}$ nanoparticle concentrations. Since the NPs have the ability to obstruct the pore space of formation, which prevents the drilling fluid from escaping to the formation. For instance, adding $1 \mathrm{wt} . \%$ of $\mathrm{SiO}_{2} \mathrm{NP}$ to Mud 3 diminished the filtration volume by $12 \%$, while adding the same amount of $\mathrm{ZnO} \mathrm{NP}$ reduced the filtration loss by $10 \%$. Furthermore, Mud 2 showed the best fluid loss control where the mud filtration reduced by $38 \%$ for $\mathrm{SiO}_{2}$ and $32 \%$ for $\mathrm{ZnO}$. Furthermore, mud filtration was reduced by $30 \%$ for Mud 1 and 31\% for Mud 4, respectively.

3.1.4. Gel Strength (GS) (10 Sec and $10 \mathrm{Min})$. Gel strength (SG) is the ability of drilling mud to enhance and sustain a gel structure whenever the drilling operation is paused. An appropriated fluid gel strength is usually required, as it would preserve the excessive circulation pressure to resume drilling activities. Figures $6(\mathrm{a})$ and $6(\mathrm{~b})$ demonstrate a comparison between 10 seconds and 10 minutes gel strengths for each set of WBM samples before and after adding $\mathrm{SiO}_{2}$ and $\mathrm{ZnO}$ NPs.

It is clear that there is a gradual reduction in the gel strength as the $\mathrm{SiO}_{2}$ and $\mathrm{ZnO}$ concentrations increase as a result of the repulsive force happening between nanoparticles and the water-based mud that causes the expansion between the nanosized particle and the water molecule with the decrease in the mud gelation. We can say that the $\mathrm{SiO}_{2}$ and $\mathrm{ZnO}$ act as dispersion agents.

3.1.5. Mud Weight (Density). The results shown in Figures $7(\mathrm{a})$ and $7(\mathrm{~b})$ demonstrate that there is little or no impact of nanomaterials on mud weights. The addition of $\mathrm{SiO}_{2}$ and $\mathrm{ZnO}$ NPs does not greatly increase the mud density. This gives an advantage in selecting NPs as a bridging agent and thus minimizes the rate of solid particles in the drilling muds, particularly when drilling a high angle hole or horizontal and deviated wells. 


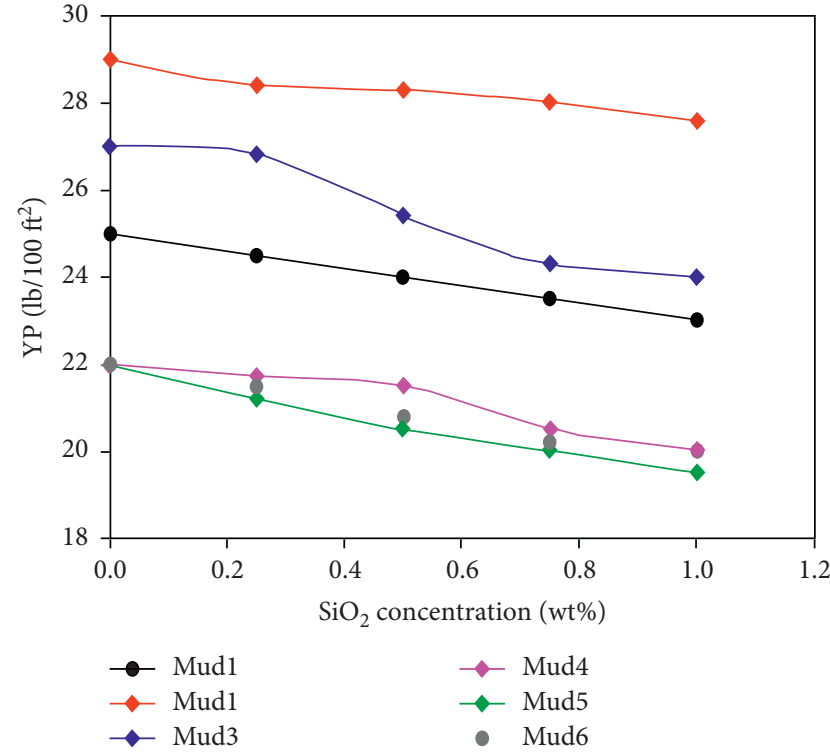

(a)

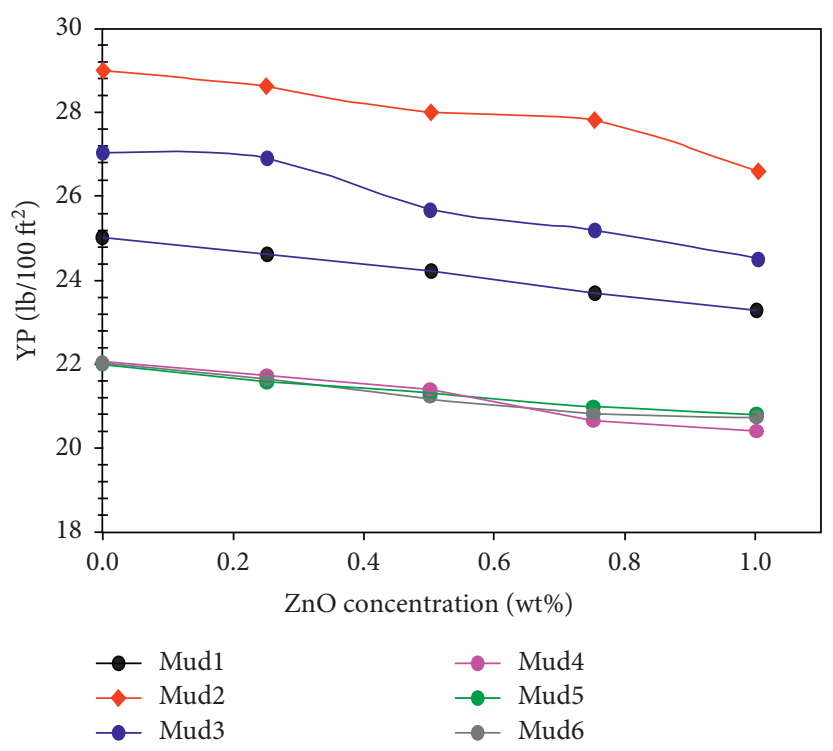

(b)

FIGURE 4: Yield point values of 6 different mud systems (a) with and without silica dioxide NPs and (b) with and without zinc oxide NPs at different concentration rates.

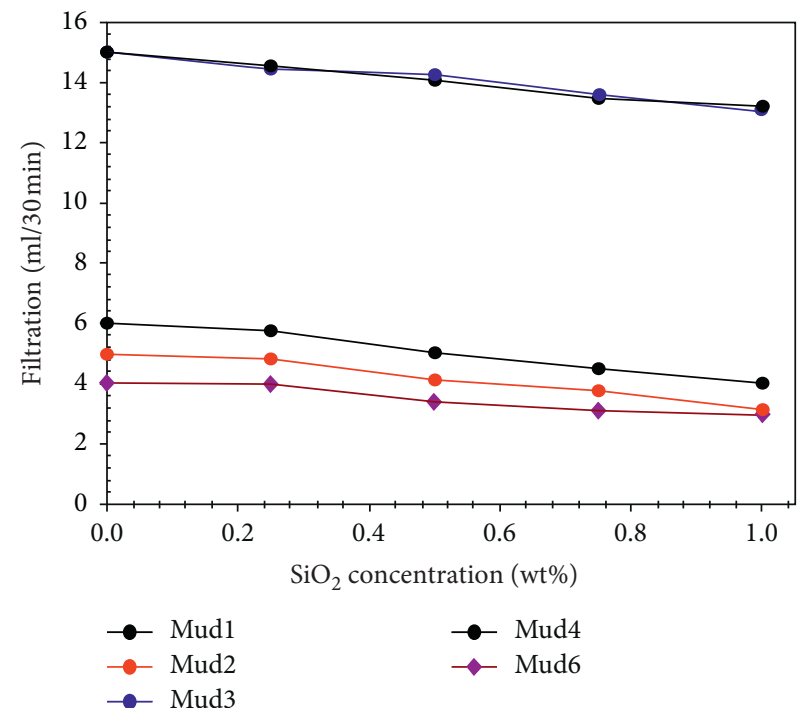

(a)

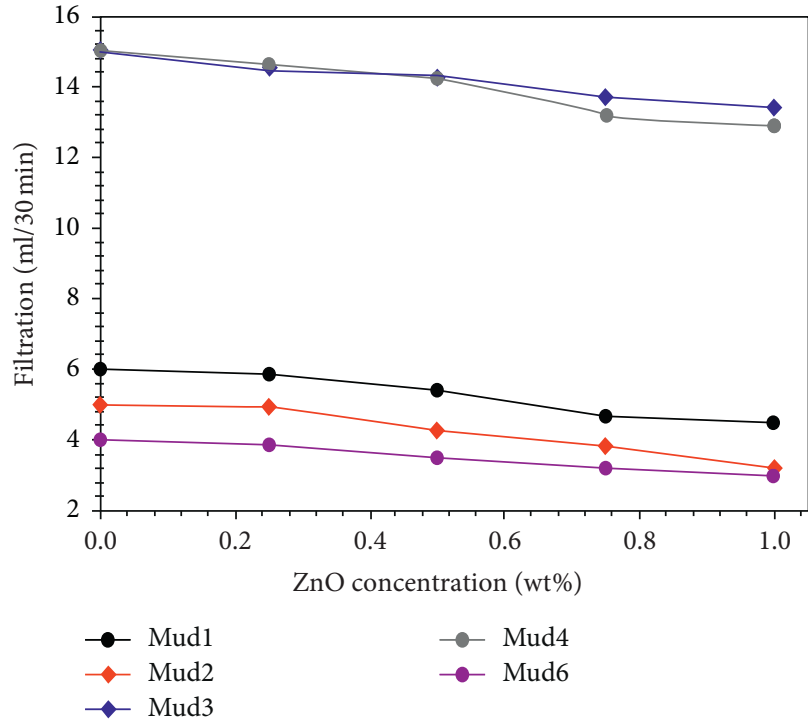

(b)

FIGURE 5: Effect of different concentrations of $\mathrm{SiO}_{2}$ and $\mathrm{ZnO}$ NPs on mud filtration loss volume $\mathrm{l}$ by (a) adding $\mathrm{SiO}_{2} \mathrm{NPs}$ and (b) adding $\mathrm{ZnO}$ NPs to the drilling muds. 

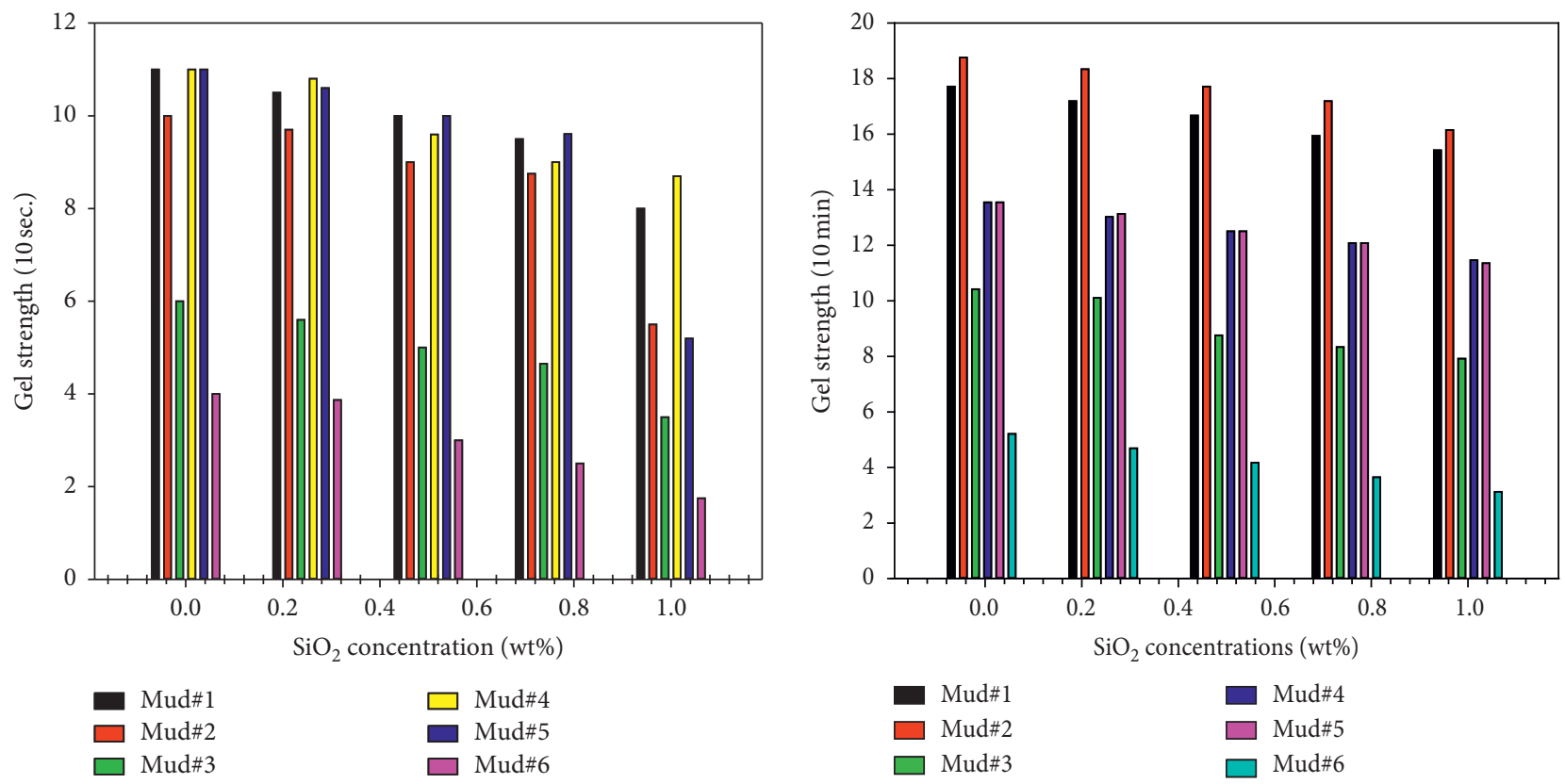

(a)
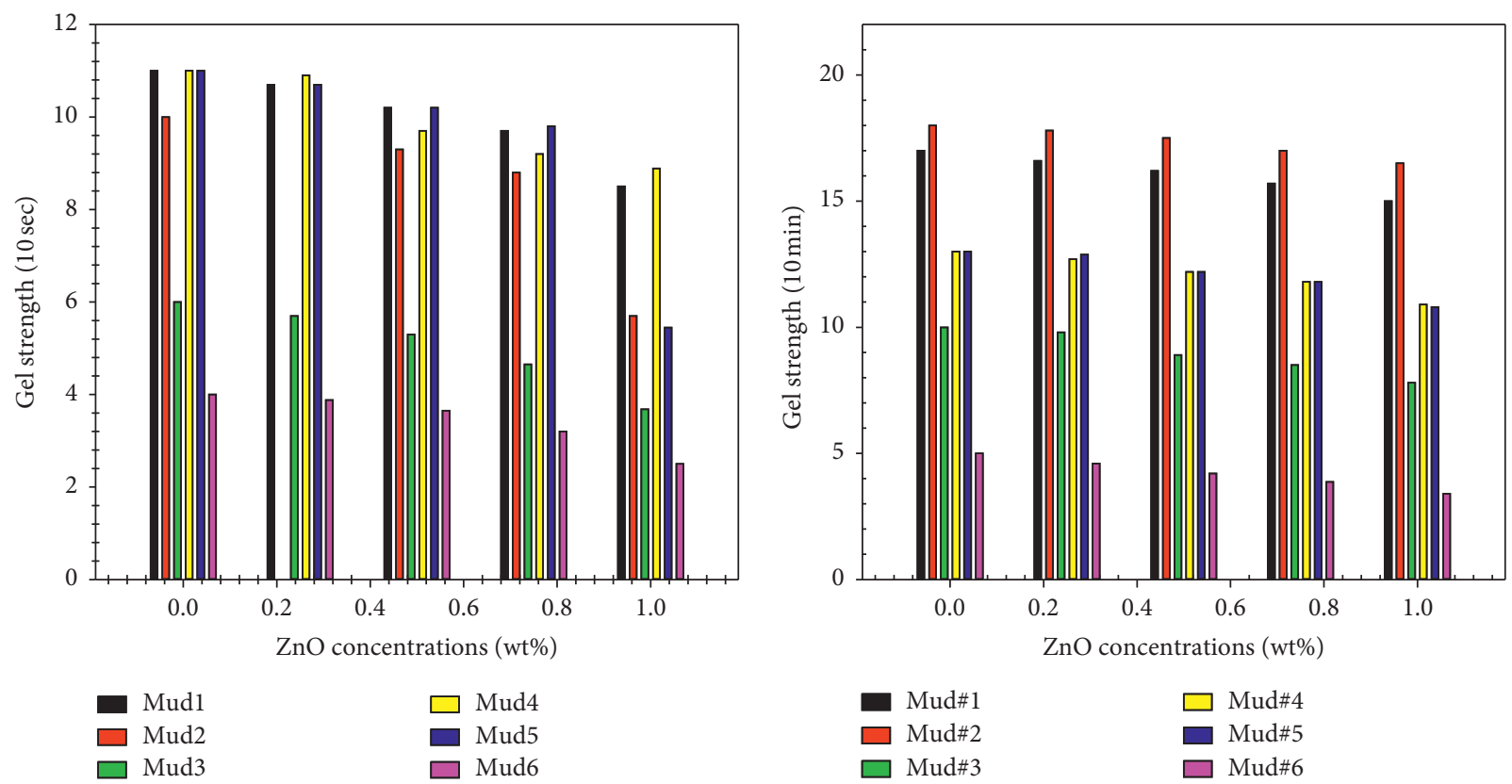

(b)

FiguRE 6: Comparison of 10 min and 10 sec gel strengths of different WBM systems at different wt.\% concentrations by (a) adding $\mathrm{SiO}_{2} \mathrm{NPs}$ and (b) adding $\mathrm{ZnO}$ NPs. 


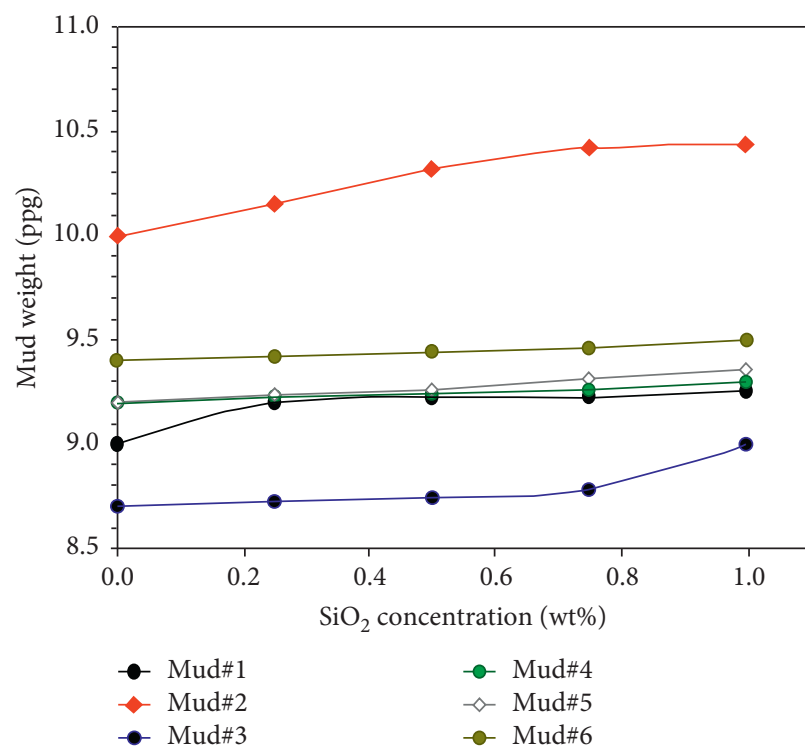

(a)

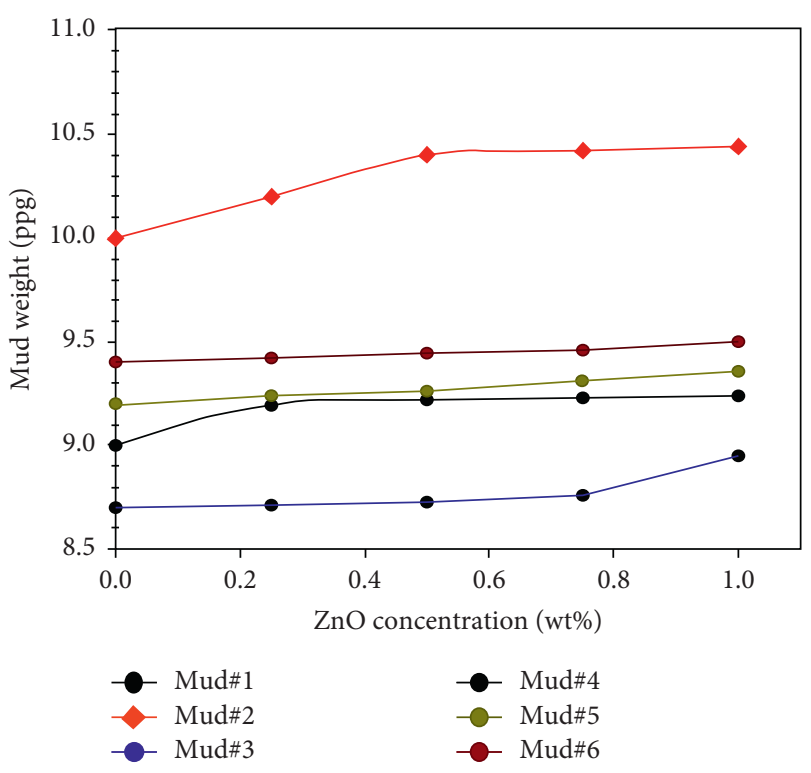

(b)

Figure 7: Density of drilling muds (a) with and without $\mathrm{SiO}_{2} \mathrm{NPs}_{\text {and }}(\mathrm{b}$ ) with and without $\mathrm{ZnO}$ NPs.

\section{Conclusions}

(1) This study presents the laboratory evaluation of adding different concentrations of $\mathrm{SiO}_{2}$ and $\mathrm{ZnO}$ nanoparticles to six conventional water-based drilling muds. From the results obtained, the following conclusions are presented:

(2) NPs can be used to solve several issues related to drilling muds, such as minimizing the thickness of mud cake, reducing the filtration volumes, and adjusting the friction factor.

(3) The water-based nanomuds can be used as an alternative to oil-based muds since they have the ability to penetrate the pore space of the shale and act as a bridging material and then strengthen the wellbore.

(4) The results indicate that there is no or minimal impact of $\mathrm{SiO}_{2}$ and $\mathrm{ZnO}$ NPs on mud weight.

(5) $\mathrm{The} \mathrm{SiO}_{2}$ and $\mathrm{ZnO}$ nanoparticles can effectively enhance the rheological characteristics of conventional waterbased muds, leading to better borehole cleaning and drilling cutting suspension. These nanosized additives can replace the standard drilling additives, and they can act as mud thinners showing a decrease in viscosity.

(6) Both NPs provided a better fluid loss control agent in comparison with conventional drilling muds, where the presence of $\mathrm{SiO}_{2}$ and $\mathrm{ZnO}$ NPs reduce the filtration volume by reducing the drilling fluid permeability.

\section{Abbreviations}

Nanoparticles

ZnO: Zinc oxide

$\mathrm{SiO}_{2}$ : Silica dioxide
WBM: Water-based mud

OBM: Oil-based mud

HPHT: High pressure high temperature

PV: $\quad$ Plastic viscosity

YP: $\quad$ Yield point

$\rho: \quad$ Density

Mw: Mud weight

GS: Gel strength

API: American Petroleum Institute

ROP: Rate of penetration.

\section{Data Availability}

The data that support the findings of this study are available from the corresponding author upon reasonable request.

\section{Conflicts of Interest}

The authors declare no conflicts of interest.

\section{Acknowledgments}

The authors are grateful to Erbil Polytechnic University and Erbil Technology College for their technical support.

\section{References}

[1] A. H. Salih, T. A. Elshehabi, and H. I. Bilgesu, "Impact of nanomaterials on the rheological and filtration properties of water-based drilling fluids," in Proceedings of the SPE Eastern Regional Meeting, Canton, OH, USA, 2016.

[2] E. A. Al-Khdheeawi and D. S. Mahdi, "Apparent viscosity prediction of water-based muds using empirical correlation and an artificial neural network," Energies, vol. 12, no. 16, p. 3067, 2019. 
[3] A. Zamani, M. Bataee, Z. Hamdi, and F. Khazforoush, "Application of smart nano-WBM material for filtrate loss recovery in wellbores with tight spots problem: an empirical study," Journal of Petroleum Exploration and Production Technology, vol. 9, no. 1, pp. 669-674, 2019.

[4] A. Parizad, K. Shahbazi, and A. Ayatizadeh Tanha, "Enhancement of polymeric water-based drilling fluid properties using nanoparticles," Journal of Petroleum Science and Engineering, vol. 170, no. 2, pp. 813-828, 2018.

[5] A. Katende, N. V. Boyou, I. Ismail et al., "Improving the performance of oil based mud and water based mud in a high temperature hole using nanosilica nanoparticles," Colloids and Surfaces A: Physicochemical and Engineering Aspects, vol. 577, pp. 645-673, 2019.

[6] A. Parizad, K. Shahbazi, and A. A. Tanha, " $\mathrm{SiO}_{2}$ nanoparticle and $\mathrm{KCl}$ salt effects on filtration and thixotropical behavior of polymeric water based drilling fluid: with zeta potential and size analysis," Results in Physics, vol. 9, pp. 1656-1665, 2018.

[7] A. Rezaei, V. Nooripoor, and K. Shahbazi, "Applicability of $\mathrm{Fe}_{3} \mathrm{O}_{4}$ nanoparticles for improving rheological and filtration properties of bentonite-water drilling fluids in the presence of sodium, calcium, and magnesium chlorides," Journal of Petroleum Exploration and Production Technology, vol. 10, no. 6, pp. 2453-2464, 2020.

[8] J. K. M. William, S. Ponmani, R. Samuel, R. Nagarajan, and J. S. Sangwai, "Effect of $\mathrm{CuO}$ and $\mathrm{ZnO}$ nanofluids in xanthan gum on thermal, electrical and high pressure rheology of water-based drilling fluids," Journal of Petroleum Science and Engineering, vol. 117, pp. 15-27, 2014.

[9] Y. Jung, M. Barry, J.-K. Lee et al., "Effect of nanoparticleadditives on the rheological properties of clay-based fluids at high temperature and high pressure," in Proceedings of the Americal Association of Drilling Engineering Conferance, Hilton Houston North Hotel, Houston, TX, USA, April 2011.

[10] M. I. Abdou, A. M. Al-Sabagh, H. E.-S. Ahmed, and A. M. Fadl, "Impact of barite and ilmenite mixture on enhancing the drilling mud weight," Egyptian Journal of Petroleum, vol. 27, no. 4, pp. 955-967, 2018.

[11] M. A. A. Alvi, M. Belayneh, S. Bandyopadhyay, and M. W. Minde, "Effect of iron oxide nanoparticles on the properties of water-based drilling fluids," Energies, vol. 13, no. 24, p. 6718, 2020.

[12] N. Al-Malki, P. Pourafshary, H. Al-Hadrami, and J. Abdo, "Controlling bentonite-based drilling mud properties using sepiolite nanoparticles," Petroleum Exploration and Development, vol. 43, no. 4, pp. 717-723, 2016.

[13] J. T. Srivatsa and M. B. Ziaja, "An experimental investigation on use of nanoparticles as fluid loss additives in a surfactantpolymer based drilling fluid," in Proceedings of the 2011 International Petroleum Technology Conference, Bangkok, Thailand, 2011.

[14] N. V. Boyou, I. Ismail, W. R. Wan Sulaiman et al., "Experimental investigation of hole cleaning in directional drilling by using nano-enhanced water-based drilling fluids," Journal of Petroleum Science and Engineering, vol. 176, pp. 220-231, 2019. 